\title{
A ESTRUTURA DA SALA DE AULA E AS NOVAS TECNOLOGIAS DIGITAIS: visão de alunos e professores do Curso de Design sobre a experiência de aprendizagem.
}

\author{
Dinara Dal Pai \\ Universidade Feevale \\ dinadalpai@hotmail.com \\ Gustavo Severo de Borba \\ Universidade do Vale do Rio dos Sinos \\ gborba@unisinos.br
}

Resumo: As evoluções tecnológicas e as transformações sociais das últimas décadas levaram a uma nova percepção sobre os espaços de aprendizagem adequados às expectativas de uma geração conectada. Profundas mudanças são necessárias no setor educacional, considerando as novas possibilidades inauguradas pelas tecnologias digitais. O processo de ensinoaprendizagem mediado por computadores pode impulsionar a inovação, mas ainda mostra limitações para a substituição integral das vivências em sala de aula. Por meio de um estudo de caso realizado com uma turma do 40 semestre do Curso de Design, este artigo analisa a experiência de aprendizagem de alunos e professores em sala de aula, considerando a relação entre Plano Político-Pedagógico, estrutura física e tecnologias digitais. $A$ análise conclui que, para impulsionar a inovação com o apoio de novas tecnologias, é preciso promover a integração entre o espaço físico, as metodologias e as mídias selecionadas.

Palavras-chave: experiência de aprendizagem, estrutura da sala de aula, tecnologias digitais, inovação, curso de design.

Abstract: Over the last decades, technological and social changes lead to a new perception about which learning spaces are appropriate to meet the expectations of the connected generation. Profound changes in the education sector are needed, considering the new possibilities inaugurated by digital technologies. Teaching-learning process mediated by computers can drive innovation in this sector, but still shows limitations to fully replace learning experiences in the classroom. By means of a case study conducted with a group of Design school students who were in the fourth semester, this article analyzes the learning experience of students and teachers in the classroom. This analysis considers the relationship between Political Pedagogical Project, physical structure of the classroom and digital 
technologies. As a conclusion, it is argued that, to drive innovation with the support of new technologies integration between physical space, methodologies and selected media is needed.

Key-words: learning experience, classroom structure, digital technologies, innovation, Design school.

\section{INTRODUÇÃO}

Nas últimas décadas do século $\mathrm{XX}$, inúmeras inovações concentradas nas tecnologias da informação remodelaram as bases materiais da sociedade em ritmo acelerado, inaugurando novas percepções para a relação entre tempo e espaço. Para Castells (1999), o novo sistema de comunicação gerou um espaço de fluxo que substituiu o espaço de lugares, da mesma forma que o tempo tornou-se intemporal. Nesse contexto, a crescente influência das inovações tecnológicas sobre os comportamentos e as vivências sociais (e vice-versa) modificou, significativamente, a forma como as pessoas interagem, enxergam o mundo e aprendem (LÉVY, 2010). No entanto, os atuais modelos de educação formal parecem não acompanhar tais transformações, deixando evidente a necessidade de inovações capazes de oferecer respostas às expectativas dos educandos e da sociedade em geral (NETTO, 2005).

Não há como ignorar o fato de que os jovens contemporâneos conhecem o computador, a Internet e o telefone celular desde que nascem, desenvolvendo, com isso, expectativas em relação à aprendizagem, as quais incluem a interatividade das tecnologias digitais (NETTO, 2005). Trata-se da denominada Geração Internet que, diferentemente das gerações anteriores, não pretende ser espectadora, mas sim agente de experiências cada vez mais interativas em ambientes permanentemente conectados (TAPSCOTT, 2010).

Animados por esta geração, os espaços de aprendizagem são constantemente ampliados para o ambiente virtual, ao mesmo tempo em que as possibilidades de uso de novas ferramentas digitais são multiplicadas. Diante disso, as instituições de educação são desafiadas por uma nova dinâmica, já que não são mais considerada a genuína fonte de informação de seus educandos (LÉVY, 2010).

Todavia, se por um lado o processo de ensino-aprendizagem mediado por computadores impulsiona a inovação do setor educacional, por outro, ainda mostra suas limitações para a substituição integral deste processo baseado nas vivências em sala de aula (HAVHOLM; STEWART, 2001). Para Balotsky e Christensen (2004), a educação nas universidades deve desenvolver uma estratégia híbrida para a mudança, combinando as vantagens da experiência em sala de aula tradicional com as novas possibilidades inauguradas pelas tecnologias da informação. Muito mais do que forma e função, o ambiente físico é um cenário carregado de significado, no qual ocorrem experiências capazes de despertar emoções e estimular determinados comportamentos (DAMAZIO et al., 2009).

A partir de um Estudo de Caso realizado com uma turma do 4ㅇ semestre de um Curso de Design, o presente artigo objetiva analisar a experiência de aprendizagem de alunos e professores em sala de aula, considerando a relação entre o Plano Político e Pedagógico do Curso, a estrutura física e as tecnologias digitais utilizadas neste espaço. 


\section{PROCESSO DE APRENDIZAGEM EM SALA DE AULA E O PAPEL DAS NOVAS TECNOLOGIAS DIGITAIS}

Historicamente, a educação é orientada segundo um modelo único de aprendizado que é focado na instrução, o qual pode ser denominado como aprendizado transmitido. Nesse modelo, o professor é percebido como um especialista, detentor e transmissor de informações, enquanto que o estudante atua como um receptor passivo, cuja principal obrigação é assimilar as informações transmitidas por meio da memorização. Assim, convencionou-se que é "através da repetição, do ensaio e da prática" que as informações podem ser memorizadas e transformadas, posteriormente, em conhecimento (TAPSCOTT, 1999, p. 126). Consequentemente, as atividades realizadas em salas de aula tendem a reforçar esse modelo a partir de práticas que induzem o aluno a decorar conteúdos padronizados e pré-estabelecidos. Dessa forma, as decisões sobre o processo de ensino são restritas ao professor, ao mesmo tempo em que se espera do aluno sua total submissão.

Para Tapscott (1999), esse modelo de ensino tem em sua essência os mesmos princípios da produção em massa que caracterizaram a era industrial. Nesse sentido, ensina-se a mesma coisa a todos os alunos, no mesmo espaço e do mesmo modo. Todavia, tal modelo generalizador do processo de aprendizagem tem se mostrado ineficiente, na medida em que se constata que cada indivíduo tem um diferente estilo de aprendizado.

$\mathrm{Na}$ perspectiva de Christensen (2009), o aprendizado baseado em computadores permite amenizar uma das principais deficiências do atual modelo de ensino, ou seja, a padronização do processo de aprendizagem. Os estudantes sempre tiveram maneiras distintas de aprender: enquanto alguns aprendem visualmente ou ouvindo, outros aprendem manipulando algo fisicamente. Atualmente, influenciados pela lógica da conexão on-line, os alunos da chamada Geração Internet consideram o modelo de aprendizado individual inadequado, uma vez que cresceram colaborando, compartilhando e criando coisas em conjunto no espaço virtual (TAPSCOTT, 2010).

No entanto, levando em conta que os computadores já estão presentes em um grande número de salas de aula, por que, até o momento, sua presença não possibilitou a transformação do tradicional modelo de ensino?

Em Cysneiros (1998, p. 15), tal situação é percebida como o reflexo da inserção das novas tecnologias em um contexto de "inovação conservadora". Com isso, na maioria dos casos, não ocorre a utilização correta dos recursos tecnológicos como mediadores do processo educativo em sala de aula e seu uso não explora todo o potencial dos equipamentos para a educação. Para o autor, as mudanças observadas até o momento são apenas aparentes, porque as transformações trazidas pelas novas tecnologias restringem-se aos meios para a transmissão das informações.

Ao encontro desse pensamento, Tapscott (1999) observa que o atual cenário das salas de aula é resultado de um processo de adaptação da tecnologia ao convencional contexto de ensino. Dessa maneira, apesar de representarem uma novidade para a educação, as novas tecnologias digitais vêm sendo utilizadas apenas para substituir antigas ferramentas, não oferecendo, assim, grandes vantagens para o processo de aprendizagem. Nesse sentido, o autor ressalta que tal situação reflete a natureza rígida do modelo convencional de ensino, no qual velhos paradigmas demonstram-se resistentes à mudança. 
Apesar disso, muitos estudos já apresentam contribuições capazes de estimular e direcionar uma reflexão acerca das diferentes possibilidades de aplicação das ferramentas digitais como estímulo para a inovação das práticas em sala de aula. $O$ quadro abaixo exemplifica essa questão:

Quadro 1 - Ferramentas utilizadas para o processo de ensino-aprendizagem

\begin{tabular}{|c|c|}
\hline Ferramentas tecnológicas/Autor & Vantagens do uso em sala de aula \\
\hline Videoconferência/Amar (2008) & $\begin{array}{l}\text { - Comunicação virtual em tempo real por meio de } \\
\text { sons e imagens; } \\
\text { - Troca de informações e conhecimentos de forma } \\
\text { interativa por pessoas que estão distantes } \\
\text { geograficamente; } \\
\text { - Participação simultânea de grupos. }\end{array}$ \\
\hline Weblog/Amar (2008) & $\begin{array}{l}\text { - Publicação de conteúdos em textos, vídeos e } \\
\text { fotografias; } \\
\text { - Participação aberta; } \\
\text { - Possibilidade de compartilhamento de } \\
\text { informações como, por exemplo, dúvidas, } \\
\text { comentários pessoais, resolução de problemas, etc.; } \\
\text { - Criação de comunidades de alunos e professores } \\
\text { interessados pelo mesmo assunto; } \\
\text { - Trabalho colaborativo. }\end{array}$ \\
\hline Simulação virtual/Lévy (2010) & $\begin{array}{l}\text { - Ampliação da imaginação individual; } \\
\text { - Compartilhamento de modelos mentais } \\
\text { (independente de sua complexidade); } \\
\text { - Formulação e exploração rápida de grande } \\
\text { quantidade de hipóteses. }\end{array}$ \\
\hline $\begin{array}{l}\text { Plataforma para avaliação/Pellegrino e } \\
\text { Quellmalz (2010); Roozenburg e Zijlstra } \\
\text { (2009) }\end{array}$ & $\begin{array}{l}\text { - Feedback imediato; } \\
\text { - Integração de conhecimentos; } \\
\text { - Geração de diagnósticos. }\end{array}$ \\
\hline Vídeos educativos/Thompson (2011) & $\begin{array}{l}\text { - Visualização do conteúdo do vídeo a qualquer hora } \\
\text { e quantas vezes for necessário; } \\
\text { - Possibilita utilizar o tempo em sala de aula para o } \\
\text { desenvolvimento de atividades práticas e exercícios } \\
\text { que necessitem do acompanhamento do professor. }\end{array}$ \\
\hline Rede Social/ Schadewitz e Zamenopoulos (2009) & $\begin{array}{l}\text { - Criação de comunidade de alunos; } \\
\text { - Troca de experiências e opiniões durante o } \\
\text { desenvolvimento do projeto. }\end{array}$ \\
\hline
\end{tabular}

Fonte: Elaborado pela autora.

A leitura do quadro reafirma o grande potencial das ferramentas tecnológicas como impulso para as transformação da sala de aula convencional. Todavia, sua adoção requer a análise permanente do valor da tecnologia para a 
aprendizagem, considerando as vantagens e também as desvantagens de seu uso no processo de ensino-aprendizagem (AMAR, 2008).

\section{METODOLOGIA}

A fim de atingir o objetivo anteriormente descrito, o presente artigo desenvolveu-se por meio de uma investigação empírica qualitativa do tipo Estudo de Caso. A pesquisa foi desenvolvida junto ao Curso de Design - Habilitação: Design da Unisinos. A escolha dessa instituição e, mais especificamente, de uma turma de alunos e professores do 4을 semestre do curso de Design como unidade de estudo (Programa de Aprendizagem 4 - PA4) foi feita levando-se em consideração o nível de inovação proporcionado pelas diretrizes do Projeto Político Pedagógico do curso em questão, o qual projetou suas atividades de formação por meio de um modelo que questiona o paradigma disciplinar. Além disso, justifica-se a escolha da referida turma pelo fato de que ela se encontra em uma etapa da formação que lhe permitiu vivenciar em sala de aula diferentes experiências e abordagens de aprendizagem.

Após a autorização para o desenvolvimento das atividades de investigação no local, o Estudo de Caso teve início com uma fase de aproximação e sensibilização dos alunos e professores do PA4 a fim de incentivar a sua participação nos três procedimentos de coleta de dados. O primeiro procedimento, a pesquisa documental, teve como objetivo apresentar um breve descritivo da Unisinos e do Curso de Design. Para tanto, foi realizado o levantamento dos principais documentos institucionais, como o Projeto Político Pedagógico - Curso de Graduação em Design e o Plano de Desenvolvimento Institucional - PDI UNISINOS.

Já o segundo procedimento, a observação de professores e alunos, ocorreu nas salas de aula do Curso de Design durante 18 períodos de atividades curriculares que ocorreram entre os dias 10 de agosto e 02 de setembro de 2011. Nesses locais, além da estrutura física, procurou-se observar as motivações para o uso das tecnologias digitais, bem como as contribuições e restrições dessas ferramentas durante o desenvolvimento das atividades propostas em sala de aula. Assim, para garantir o registro de todos os detalhes observados, foram feitas anotações e fotografias. A Tabela 1 apresenta algumas informações importantes sobre os períodos observados.

Tabela 1. Detalhamento dos períodos de observação da sala de aula.

\begin{tabular}{lllll} 
Observação (0) & Data & Local & Quant. de alunos & Quant. de professores \\
O-1* & 01.08 .11 & Porto Alegre & 0 & 10 \\
O-2 & 15.08 .11 & Porto Alegre & 12 & 2 e 1 estagiária \\
O-3 & 15.08 .11 & Porto Alegre & 14 & 1 \\
O-4 & 16.08 .11 & São Leopoldo & 14 & 1 \\
O-5 & 17.08 .11 & São Leopoldo & 10 & 1 \\
O-6 & 18.08 .11 & São Leopoldo & 10 & 1 \\
O-7 & 18.08 .11 & São Leopoldo & 10 & 1 \\
O-8 & 18.08 .11 & São Leopoldo & 6 & 1 \\
O-9 & 19.08 .11 & Porto Alegre & 12 & 1 \\
O-10 & 25.08 .11 & São Leopoldo & 6 & 1 \\
O-11 & 29.08 .11 & São Leopoldo & 13 & 1 \\
O-12 & 29.08 .11 & São Leopoldo & 12 & 1 e 1 estagiária \\
O-13 & 29.08 .11 & São Leopoldo & 8 & 1 \\
O-14 & 30.08 .11 & São Leopoldo & 8 & 1 \\
\hline
\end{tabular}




\begin{tabular}{lllll}
\hline O-15 & 30.08 .11 & São Leopoldo & 10 & 1 \\
O-16 & 01.09 .11 & São Leopoldo & 10 & 1 \\
O-17 & 02.09 .11 & Porto Alegre & 12 & 2 e 1 estagiária \\
O-18 & 02.09 .11 & Porto Alegre & 13 & 1 \\
\hline
\end{tabular}

*Reunião de professores

Fonte: Elaborada pela autora (2012).

Por fim, entrevistas finalizaram o processo de coleta de dados, sendo realizadas pela pesquisadora junto a 4 alunos e 4 professores do PA4 visando conhecer as suas experiências e percepções acerca do cotidiano de aprendizagem em sala de aula. Para garantir o máximo aproveitamento das informações coletadas, as entrevistas foram gravadas em áudio e transcritas. As tabelas 2 e 3 apresentam o detalhamento do período em que foram realizadas as entrevistas, bem como do perfil dos entrevistados.

Tabela 2. Detalhamento das entrevistas realizadas com os alunos.

\begin{tabular}{lllll}
$\begin{array}{l}\text { Entrevista } \\
\text { alunos (EA) }\end{array}$ & Data & Local & Sexo & Idade \\
\hline EA-1 & 18.08 .11 & São Leopoldo & Feminino & 21 anos \\
EA-2 & 19.08 .11 & Porto Alegre & Masculino & 18 anos \\
EA-3 & 19.08 .11 & Porto Alegre & Masculino & 22 anos \\
EA-4 & 29.08 .11 & Porto Alegre & Feminino & 18 anos \\
\hline
\end{tabular}

Fonte: Elaborada pela autora (2012).

Tabela 3. Detalhamento das entrevistas realizadas com os professores.

\begin{tabular}{llllll}
$\begin{array}{l}\text { Entrevista } \\
\text { Professor } \\
\text { (EP) }\end{array}$ & Data & Local & $\begin{array}{l}\text { Tempo } \\
\text { de } \\
\text { docência }\end{array}$ & Sexo & Idade \\
EP-1 & 15.08 .11 & Porto Alegre & 7 anos & Feminino & 32 anos \\
EP-2 & 29.08 .11 & Porto Alegre & 20 anos & Masculino & 52 anos \\
EP-3 & 30.08 .11 & Porto Alegre* & 10 anos & Masculino & 37 anos \\
EP-4 & 31.08 .11 & Porto Alegre & 4 anos & Masculino & 38 anos \\
\hline
\end{tabular}

Fonte: Elaborada pela autora (2012).

*Entrevista por Skype.

A análise dos materiais coletados no Estudo de Caso teve como base o modelo de Yin (2001), o qual apresenta o conceito de triangulação, propondo relacionar as informações coletadas.

\section{ANÁLISE E APRESENTAÇÃO DOS RESULTADOS}

\subsection{Contexto de Estudo}

A turma de alunos e professores de Design, unidade de estudo dessa pesquisa, integra o Curso de Graduação em Design da Unisinos, o qual foi desenvolvido em 2006 
por meio de uma parceria com o POLI.design, Consorzio del Politecnico di Milano (centro de pesquisa e de formação em Design da Itália). De acordo com o seu Projeto Político Pedagógico (2006), o curso vem oferecer à comunidade regional uma nova perspectiva acerca do design, fortemente apoiada nos conceitos de design estratégico e inovação.

O curso estrutura-se a partir de 6 programas de aprendizagem, cada um com duração de um semestre letivo. Por meio desses programas, busca-se estabelecer uma estrutura curricular na qual diferentes conhecimentos podem ser articulados através do desenvolvimento de projetos que atendem à demanda de um cliente real. Para tanto, cada PA tem como base um Ateliê de Projeto, sendo este o espaço central que promove a interdisciplinaridade pertinente para a atividade. Na perspectiva de um dos professores entrevistados, esse modelo desafia a lógica do professor como o único detentor do conhecimento, uma vez que se torna necessário planejar aulas e conteúdos alinhados ao contexto do projeto em questão. Dessa forma, é provável que o professor depare-se com o desafio da busca de novos conhecimentos ou abordagens nunca antes trabalhados pelos modelos disciplinares em sua área. Na opinião do entrevistado,

esse processo os alunos ganham demais, os professores aprendem muito porque eles têm que construir pontes com áreas de conhecimento que não são necessariamente deles. Ele se obriga a também pesquisar, pensar, articular e a construir as conexões. (EP-3)

Dessa forma, com base no conceito de PA, o curso busca romper a tradicional linearidade curricular por meio de um modelo que visa promover a constante articulação de conteúdos teóricos e práticos, bem como entre as áreas de conhecimento envolvidas na formação profissional. A maioria dos professores participantes desta pesquisa acredita nos benefícios do modelo do PA, ainda que ele tenha passado por modificações em sua estrutura, já previstas pelo Projeto Político Pedagógico (2005), contribuindo, desta forma, para adequar a proposta à realidade prática do curso.

Como eu te disse, nem tudo é perfeito, nem tudo tá saindo perfeito, mas coisinhas a gente vai corrigindo de um ano para o outro. (EP-4)

Diante disso, é possível observar um ambiente institucional favorável à mudança, uma vez que, independente do nível de inovação, busca-se romper com o modelo de ensino superior baseado em disciplinas independentes. Para Borjas (2006), a mudança no setor educacional somente acontecerá se antes existir um ambiente aberto para a inovação. Para tanto, a gestão educacional desempenha um papel fundamental, à medida que possibilita a criação e a internalização de iniciativas inovadoras na rotina das instituições de ensino, através de um processo que permite erros e acertos, assim como manifesto pelo professor entrevistado.

O Programa de Aprendizagem 4 (PA4), período no qual se desenvolveu a presente pesquisa, ocorre no 40 semestre das atividades curriculares do curso. De forma geral, seus objetivos são: "compreender os elementos que integram o sistemaproduto, bem como a sua relação com a cultura, com os métodos e com os instrumentos pertinentes para o desenvolvimento de projetos estratégicos; construir uma estratégica de sentido para a existência do produto, por meio da compreensão 
das possibilidades efetivas de processos do design aplicadas a produtos materiais e imateriais" (AJUSTES CURRICULARES DO CURSO DE BACHARELADO EM DESIGN, 2007).

Para tanto, o PA4 oferece atividades acadêmicas que buscam desenvolver as competências necessárias para que o aluno alcance os objetivos determinados pelo semestre. Dessa forma, além do Ateliê de Projeto 4, que centraliza todo o conhecimento, o aluno deve cursar todas as atividades previstas pelo plano curricular.

$\mathrm{Na}$ busca pela integração dos diferentes conhecimentos, observou-se que, em alguns casos, os professores encontraram dificuldades para relacionar as atividades propostas em sala de aula ao tema de projeto trabalhado pelo Ateliê de Projeto. Essa dificuldade foi ainda maior nas atividades essencialmente instrumentais que buscavam trabalhar a habilidade técnica do aluno. Diante disso, os alunos entrevistados foram unânimes ao afirmar que experiências anteriores, vivenciadas em outros programas de aprendizagem (PA1, PA2 e PA3), não garantiram efetivamente a proposta de integração dos diferentes saberes. Nas palavras de uma das alunas entrevistas,

Houve um semestre, acho que foi o PA2, em que a gente não sentiu, assim, tanta ligação entre os conteúdos. Também acho que depende muito do foco do cliente, né? Da parceria que nós temos no semestre com a empresa. (EA1)

Por meio das observações e das entrevistas foi possível identificar alguns fatores que influenciam essa percepção do aluno. Dentre eles, é possível citar: (a) as características gerais do cliente (setor, fornecimento de informações, disponibilidade para o acompanhamento do projeto); (b) os objetivos do projeto em questão; (c) o empenho e a comunicação constante entre os professores; (d) a coordenação das atividades acadêmicas e do processo projetual desenvolvido durante o Ateliê; e (e) a participação e empenho do aluno nas atividades propostas.

Ao pensar na relação entre os atores sociais do contexto da sala de aula e as tecnologias digitais, há dois pontos a serem ressaltados. $O$ primeiro deles diz respeito à participação e empenho dos alunos nas atividades propostas, uma vez que se observou frequentes atrasados na chegada dos estudantes, conforme é descrito a seguir:

\begin{abstract}
As atividades observadas iniciaram com poucos alunos em sala de aula, fazendo com que o professor manifestasse sua preocupação com as ausências. Com o passar do tempo, os alunos vão chegando, alguns, com mais de 20 minutos de atraso. Nesse momento, as discussões já haviam iniciado e percebe-se que o professor perde um considerável tempo retomando o conteúdo com os alunos que chegaram depois do horário. Mesmo assim, torna-se difícil para o aluno acompanhar as discussões que estavam em andamento. Dessa forma, observa-se que os alunos atrasados abrem seus computadores e acessam blogs e redes sociais que não estão, aparentemente, relacionados ao tema discutido em sala de aula. (0-12)
\end{abstract}

Nesse contexto, foi possível observar que a rotina de atraso dos alunos dificultava o planejamento do professor e o desenvolvimento de uma experiência de aprendizagem compartilhada pela turma, uma vez que ao se inserirem tardiamente à discussão os alunos acabavam perdendo os primeiros estímulos da aula. Dessa forma, 
a tecnologia digital por vezes configurou-se como uma válvula de escape para o aluno, e $o$ acesso às redes sociais foi observado com grande frequência.

Segundo Tapscott (2010), tal situação pode ser o reflexo da incompatibilidade entre os modos de pensar da Geração Internet e de seus professores. Para o autor, os atuais modelos de ensino, baseados em aulas expositivas, são responáveis pelo tédio observado em muitos alunos que são acostumados a interagir nos meios eletrônicos. A entrevista abaixo revela que os professores têm consciência disso, mas ainda encontram dificuldade para modificar seu modelo de trabalho.

(...) eu estava em uma reunião sábado, os professores trouxeram exemplos e falaram sobre power point dizendo que as vezes essa ferramenta é chata em uma disciplina de teoria. A partir disso, eu estou pensando como mudar essa situação em relação aos alunos. (EP-2)

O segundo ponto implicado na relação entre os atores sociais do contexto da sala de aula e as tecnologias digitais diz respeito à comunicação entre os professores, à medida que este é um fator fundamental para que a integração dos diferentes conhecimentos seja efetivada. Nesse sentido, constatou-se que, apesar de existir em média 2 encontros presenciais entre os professores durante o semestre, a comunicação proporcionada por essas reuniões pareceu, por vezes, insuficiente diante do objetivo proposto pelo PA.

Essa constatação se fez por meio da observação do infrequente diálogo entre os professores, ou outros meios que possibilitassem a compreensão de todas as atividades que vinham sendo desenvolvidas por cada atividade acadêmica individualmente, dificultando a acompanhamento integral do processo de aprendizagem. Contudo, quando necessário, os professores faziam o uso ferramentas digitais para o compartilhamento de arquivos e envio de e-mails, evidenciando o potencial da tecnologia, ainda que pouco explorado, para a comunicação indispensável entre os docentes frente à proposta curricular.

Tendo isso em vista, é possível afirmar que com a tecnologia digital na sala de aula uma nova experiência de ensino-aprendizagem é apresentada ao professor e ao aluno. E junto com ela, surgem, também, novos desafios, uma vez que o uso atribuído à tecnologia é o que vai definir o seu valor para a aprendizagem nesse espaço.

\subsection{A estrutura física da sala de aula}

O espaço físico da sala de aula reflete e produz valores pedagógicos por meio das atividades e interações sociais que o ambiente favorece (MONAHAN, 2002). Nessa perspectiva, a estrutura da sala de aula incorpora e transmite significados que influenciam, diretamente, na experiência de aprendizagem vivenciada por professores e alunos nesse espaço.

Para Schratzenstaller (2010), o modelo de sala de aula presente hoje na maioria das instituições de ensino reproduz a estrutura da sala de aula projetada segundo os moldes de disciplina e ordem do século XIX. Com isso, nota-se claramente a incompatibilidade entre a forma e a função, ao passo que os estudantes contemporâneos estão imersos em um mundo de tecnologias que inauguram novas perspectivas sobre a aprendizagem. Dessa forma, enquanto que a maioria dos sistemas sociais muda junto com os avanços da tecnologia, a sala de aula permanece 
inalterada e transmite ao aluno uma mensagem disciplinar defasada e incompatível com o seu pensamento e com a almejada postura ativa do aluno no processo de aprendizagem.

Durante o período de observação da sala de aula do PA4, o descompasso entre a estrutura e os objetivos do curso de design foi evidente nos três espaços físicos observados, a saber, duas salas tradicionais e um laboratório de informática. Nesse contexto, evidenciou-se o paradoxo de uma instituição e de um curso que se esforçam pela inovação e, no entanto, buscam nos "moinhos de ensino" do passado a ambiente para mudar (SCHRATZENSTALLER, 2010).

O laboratório de informática (Figura 1), situado no Campus Porto Alegre, foi utilizado somente pela atividade acadêmica Oficina Digital 3D. Nesse espaço, observou-se que a presença dos computadores tornava o laboratório um ambiente rígido, sem a possibilidade de mudanças simples na disposição das mesas que se encontravam enfileiradas de frente para o quadro. Durante as atividades, todos os alunos contavam com pelo menos um computador, no entanto, o excesso de máquinas e a configuração da sala de aula limitavam o movimento do professor e dos alunos. Dessa forma, em grande parte do tempo, o professor permaneceu sentado em sua mesa, orientando as atividades a partir de uma projeção.

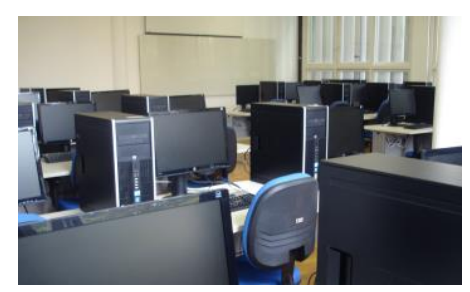

Figura 1 - Laboratório de informática do Campus Porto Alegre.

Fonte: Registrada pela autora (2012).

Assim, a restrição do espaço de circulação somada à luminosidade limitada do local (necessária à visualização das telas dos computadores e projeção) tornaram o ambiente escuro e monótono, incentivando, com isso, a sonolência dos alunos, que pôde ser observada em frequentes bocejos. Para Monahan (2002), o contexto tecnológico apresenta novos desafios para o projeto de sala de aula, que agora deve levar em conta o desenvolvimento de mobiliários que facilitem o uso dos computadores sem abrir mão da flexibilidade do espaço. Ao mesmo tempo, também a iluminação deve ser estudada para solucionar os problemas de brilho e tornar o ambiente agradável para a realização das atividades propostas.

Harris (2010) destaca ainda a necessidade de o espaço físico da sala de aula estimular positivamente os cinco sentidos para propiciar o bem-estar e incentivar a aprendizagem do aluno. Da mesma forma, observa que

sentir-se bem ou não em um determinado espaço de sala de aula depende muito de como o ambiente está disposto, se suas estruturas arquitetônicas são acolhedoras ou não; se as condições de permanência são agradáveis ou desagradáveis; se as áreas são arejadas e iluminadas; se há espaço adequado para acolher o número de alunos (PASSOS; VEIGA, 2008, p. 289).

Diante do exposto, constata-se que muitos dos pontos apresentados por Passos e Veiga (2008) merecem ser repensados no caso do laboratório de informática, 
principalmente porque se observou que o somatório de algumas características do local não tornava a permanência agradável. Já, no caso da segunda sala de aula observada no Campus Porto Alegre, utilizada pelo Ateliê de Projeto 4 (Figura 2) e pela atividade acadêmica de Teoria do Design, a flexibilidade na disposição das mesas, a boa iluminação e o espaço para circulação tornaram o ambiente mais agradável.

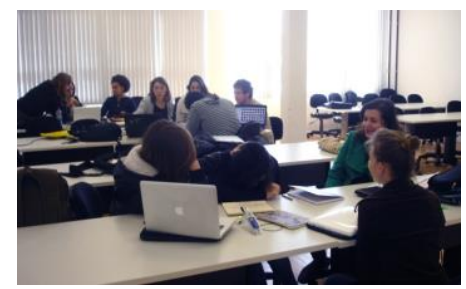

Figura 2 - Sala de aula do Campus Porto Alegre.

Fonte: Registrada pela autora (2011).

Em relação aos móveis e à sua configuração no espaço, observou-se que

\begin{abstract}
as mesas são grandes e cada uma comporta tranquilamente dois alunos. As cadeiras têm rodinhas e seu estofamento as torna confortáveis. Ao entrar na sala, os móveis encontram-se organizados de forma linear e orientam a visão do aluno para a parte da frente da sala, onde ficam o quadro e a estrutura para a projeção. (0-2)
\end{abstract}

Todavia, se em um primeiro momento essa sala de aula parece favorável à permanência e à aprendizagem, logo é possível perceber que a organização do espaço sugere obstáculos à interação de alunos e professores. Para Mäkitalo-Siegl et al. (2010), a configuração e a arquitetura da sala de aula influenciam o comportamento e a postura dos atores sociais inseridos nesse ambiente. Segundo o autor, uma sala de aula onde o professor assume uma posição frontal cria a expectativa segundo a qual os alunos devem permanecer em silêncio e ouvir o professor, que está na posição de protagonista e, por esse motivo, tem o direito de falar.

Diante disso, não é surpreendente que os alunos observados assumissem posições no espaço da sala de aula menos favoráveis à interação com o professor, uma vez que o ambiente Ihes sugeria limites à participação. $O$ trecho a seguir exemplifica essa situação:

[...] as mesas estavam divididas em duas colunas que eram orientadas para o quadro. No entanto, diante de uma grande quantidade de classes em desuso, chamou a atenção o fato de todos os alunos estarem em um único lado, sendo que este era, justamente, o lado que os distanciava das professoras e dificultava o diálogo. (0-17)

Destaca-se que, durante os períodos de observação do Ateliê de Projeto 4, a disposição do mobiliário da sala de aula não foi alterada. Porém, nas aulas de Teoria do Design, foi possível observar dois contextos distintos que deixaram clara a importância da configuração da sala de aula para a interação entre professores e alunos. Assim, enquanto que na primeira aula as mesas estavam dispostas na forma de "U" (Figura 3), na segunda (Figura 4) organizou-se uma grande mesa retangular onde todos os alunos ficaram próximos um do outro, bem como do professor. 


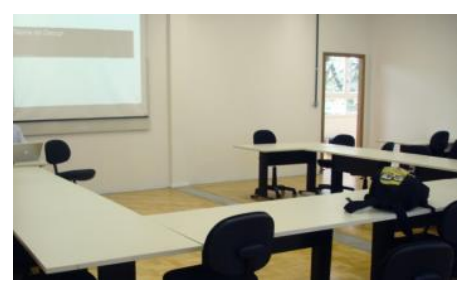

Figura 3 - Configuração da sala de aula utilizada pelo Curso de Design no Campus Porto Alegre durante a atividade acadêmica de Teoria do Design no dia $\mathbf{1 5 . 0 8 . 1 1}$

Fonte: Registrada pela autora (2011).

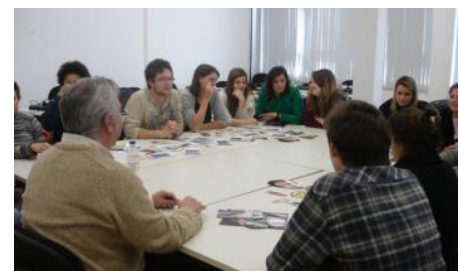

Figura 4 - Configuração da sala de aula utilizada pelo Curso de Design no

Campus Porto Alegre durante a atividade acadêmica de Teoria do Design no dia

02.09.11

Fonte: Registrada pela autora (2011).

A mudança premeditada da estrutura da sala de aula foi motivada por algumas reuniões de professores e pelo desenvolvimento da presente pesquisa, conforme pode ser evidenciado na fala do professor durante a realização de sua entrevista:

[...] pra mim o principal é colocar o aluno em uma posição onde ele tem que trocar, ele não pode ficar escondido atrás de uma mesa. Ele tem que ficar exposto ali, em volta de uma mesa. E vai ser minha tentativa da sexta-feira. Eu vou fazer uma mesa retangular e eles vão ficar em volta. E eu vou procurar ficar no centro em um dos lados maiores e vou ver se modifica, assim, a relação. A maneira como ensino teoria. (EP-2)

A partir dessa mudança estrutural, o professor estabeleceu uma nova relação com o aluno, uma vez que a mesa retangular terminou com a ideia de frente e fundo da sala de aula. Com essa alteração simples, foi possível observar transformações significativas na postura do aluno que, inserido nesse contexto, tornou-se mais ativo e motivado para a aprendizagem.

Destaca-se, porém, que a mudança da estrutura veio acompanhada de novos métodos pedagógicos que também encorajavam a participação. Dessa forma, além de reforçar a importância do espaço físico, esse "experimento", conforme chamou o professor, possibilitou observar a forte relação entre método e estrutura. Nesse sentido, Johnson e Lomas (2005) destacam que a concepção da sala de aula deve levar em conta os princípios de aprendizagem significativos para a instituição, bem como as atividades e as metodologias previstas para esse espaço.

$\mathrm{Na}$ observação da sala de aula do Campus São Leopoldo (Figura 5), onde ocorreu a maioria das atividades acadêmicas do semestre, novamente o local apresentou um grande número de mesas em relação à quantidade de alunos. Todavia, assim como aconteceu no laboratório de informática, o espaço reduzido dificultava a 
circulação dos professores pela sala de aula e não permitia que as mesas fossem deslocadas com facilidade. Dessa forma, em todas as atividades observadas nesse espaço, a disposição das mesas permaneceu exatamente igual, ou seja, estas se encontravam posicionadas de frente para quadro e para a projeção.

Figura 5 - Sala de aula do Campus São Leopoldo

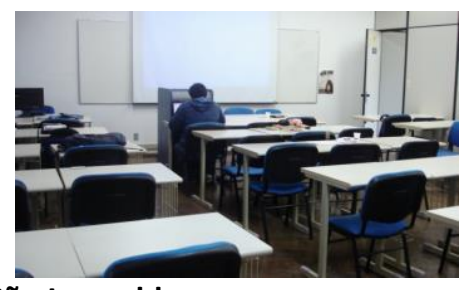
Fonte: Registrada pela autora (2011).

Somando-se a isso, outros problemas menores foram ainda identificados, como, por exemplo, o falta de isolamento acústico entre as salas de aula, o que permitia escutar conversas da turma ao lado. Outra questão constatada foi a dificuldade de trabalhar com as projeções devido à iluminação inadequada.

Durante a aula, os professores percebem um problema na estrutura da sala de aula: as luzes não podem ser desligadas parcialmente. Para que a projeção fique visível é necessário deixar a sala totalmente escura. (0-12)

Diante da rigidez e da previsibilidade arquitetônica das estruturas das salas de aula observadas, destaca-se que inúmeros autores (HARRIS, 2010; JOHNSON; LOMAS, 2005; MÄKITALO-SIEGL et al., 2010; MONAHAN, 2002) concordam que a flexibilidade dos espaços é um fator extremamente importante para a adequação dos ambientes às novas gerações de alunos. Nesse sentido, Monahan (2002) elucida que tanto as propriedades físicas internas como as forças sociais abstratas podem influenciar o significado do termo "flexibilidade" em projetos de sala de aula.

Nessa perspectiva, a flexibilidade física está relacionada à possibilidade de ajustes e modificações do espaço de acordo com as necessidades práticas dos estudantes. Já, no nível abstrato, a flexibilidade refere-se à capacidade do espaço para acomodar mudanças imprevisíveis, tais como mudanças demográficas, necessidades específicas da comunidade ou novas políticas.

Nas três salas de aula observadas por este estudo, a presença de Internet sem fio facilitou o uso frequente de computadores pessoais portáteis, os quais eram posicionados sobre as mesas. Porém, ficou evidente que a presença desses computadores em sala de aula era motivada pelo interesse do aluno, enquanto que a maioria das metodologias observadas não previa o uso desse dispositivo. Para Harris (2010), a sala de aula contemporânea deve buscar novas inspirações nas possibilidades inauguradas pelos avanços das tecnologias de informação e comunicação. Dessa forma, a diferença entre pedagogia, tecnologia, espaço e arquitetura deve ser eliminada para, assim, tornar o ambiente da sala de aula um espaço apropriado para a aprendizagem do estudante do século XXI.

\section{CONCLUSÃO}

O presente estudo analisou salas de aula frequentas por alunos do curso de Design e verificou que as mesmas desfavorecem a interação fundamental entre o 
professor e o aluno. Assim, diante de uma estrutura que limita o diálogo aberto entre os atores sociais deste espaço, a tecnologia digital acessada pelo uso de computadores portáteis, por vezes, foi o meio pelo qual o aluno encontrou espaço para se expressar e interagir durante o horário da aula.

Destacam-se ainda a convivência de duas gerações na sala de aula, a do professor e do aluno, as quais compreendem o processo de aprendizagem de maneira distinta. Para a maioria dos professores entrevistados e observados, a tecnologia digital não é um recurso inerente à sala de aula, fato que confirma que sua inserção no âmbito educacional deu-se a partir de um processo de substituição que não considerou as inteiras vantagens desses artefatos para a educação. Frente a isso, não é surpreendente que a tecnologia digital não encontre hoje na sala de aula um ambiente favorável e que o seu uso para o ensino seja restrito, ainda que possa impulsionar ambientes de aprendizagem.

Diante das reflexões estabelecidas em torno da análise das salas de aula da turma de alunos e professores do PA4, evidencia-se a incompatibilidade entre a estrutura, os métodos e as tecnologias usadas. Dessa forma, é possível ponderar que a dificuldade do PA4 para efetivar sua proposta de articulação dos conhecimentos pode estar, justamente, na incompatibilidade entre esses aspectos fundamentais à experiência de aprendizagem. Acredita-se que esse fato esteja dificultando a transformação do modelo mental de alunos e professores em relação à sala de aula e às dinâmicas propostas pelo modelo de PA.

\section{REFERÊNCIAS}

AMAR, Victor Manuel. Tecnologías de la Información y la Comunicación, Sociedad y

Educación (Sociedad, e-herramientas, professorado y alumnado). Madrid: Editora Tébar, 2008.

BALOTSKI, Edward; CHRISTENSEN, Edward. W. Educating o Modern Business Workforce: An Integrated Educational Information Tecnology Process. Sage Publication, p.148-170, 2004.

CASTELLS, Manuel. A Sociedade em Rede. 6ạ ed. São Paulo: Paz e Terra, 1999.

CHRISTENSEN, Clayton M. Inovação na sala de aula: como a inovação de ruptura muda a forma de aprender. Porto Alegre: Bookman, 2009.

CUDD, Mike; LIPSCOMB, Thomas; TANNER; Jonh. Technology in the Classroom: An Assessment of Hardware and Software Use in Finance Instruction. Journal of Education for Business, p. 244-248, 2003.

CYSNEIROS, Paulo G. Novas Tecnologias na Sala de Aula: melhoria do ensino ou inovação conservadora. In: IX ENDIPE, 1998, Águas de Lindóia. Anais... Águas de Lindóia: 1998. p. 199-216.

DAMAZIO, Vera; DAL BIANCO, Bianca; LIMA, Julia; MENEZES, Cristiane. Design and Emotion: some thoughts on users, things and feelings. International Association of Societies of Design Research, p. 2727-2734, 2009.

HARRIS, Stephen. The Place of Virtual Pedagogic and Physical Space in 21st Century Classroom. Sydney: Sydney Centre for Innovation in Learning, 2010. 
JOHNSON, Chris; LOMAS, Cyprien. Design of the Learning Space. EDUCAUSE review, p.16-28, 2005.

LÉVY, Pierre. Cibercultura. 3 ed. São Paulo: Editora 34, 2010.

MÄKITALO-SIEGL, Kati; ZOTTMANN, Jan; KAPLAN, Frederic; FISCHER, Frank. Classroom of the Future. Orchestrating Collaborative Space. Rotterdam: Sense Publishers, 2010.

MONAHAN, T. Flexible space \& built pedagogy: Emerging IT Embodiments. Inventio, v. 4, n. 1, p. 1-19, 2002.

NETTO, Antônio A. O. Novas tecnologias \& universidades: da didática tradicionalista à inteligência artificial: desafios e armadilhas. Petrópolis: Vozes, 2005.

PASSOS, Alencastro; VEIGA, Ilma. Aula: Gênese, dimensões, princípiose práticas. Campinas: Papirus, 2008.

SCHRATZENSTALLER, Andreas. The classroom of the past. In: MÄKITALO-SIEGL, Kati; ZOTTMANN, Jan; KAPLAN, Frederic; FISCHER, Frank. Classroom of the Future.

Orchestrating Collaborative Space. Rotterdam: Sense Publishers, 2010. p. 15-40.

TAPSCOTT, Don. A hora da geração digital: como que os jovens que cresceram usando a internet estão mudando tudo, da empresa ao governo. Rio de Janeiro: Agir, 2010.

Geração Digital: a crescente e irreverssível ascensão da geração net.

São Paulo: Makron Books, 1999.

PELLEGRINO, James. W.; QUELLMALZ, Edys. S. Perspectives on the integration of

Tecnology and Assessement. Journal of Research on Tecnology in Education. v. 43, n. 2, p. 119-135, 2010.

THOMPSON, C. 2011. How Khan Academy Is Changing the Rules of Education.

Disponível em: http://www.wired.com/magazine/2011/07/ff_khan/. Acessso em: set. 2011.

UNISINOS. Ajustes Curriculares do Curso de Bacharelado em Design. Curso de Design Habilitação: Design. São Leopoldo: Editora Unisinos, 2007.

UNISINOS. Projeto Político Pedagógico Curso Graduação em Design. São Leopoldo: Editora Unisinos, 2006. 